\title{
NILAI KARAKTER DALAM PARNO ADAT PERNIKAHAN DI KECAMATAN SIULAK KABUPATEN KERINCI
}

\author{
Mina Zahara \\ Fakultas Adab dan Humaniora UIN STS Jambi \\ minazahara19@uinjambi.ac.id
}

\begin{abstract}
Abstrak
Parno merupakan salah satu bentuk sastra lisan, Parno Adat pernikahan yang ada di Kecamatan Siulak berisikan tentang nasehat-nasehat bagaimana seharusnya adab seorang isteri dan suami ketika sudah berumah tangga dan mengajarkan aturan hidup bermasyarakat dengan keluarga pasangan. Parno digunakan dalam budaya masyarakat kerinci dalam kurun waktu yang cukup lama. Salain itu didalam Parno juga terdapat sumbangan berharga dari ajaran Islam dalam melengkapi berbagai aktifitas adat di Kerinci Parno adalah suatu bentuk karya lisan yang lahir dan berkembang dari masyarakat tradisional yang disebarkan dalam bentuk relatif tetap atau dalam bentuk standar disebarkan diantara kolektif tertentu dari waktu yang cukup lama. Nilai-nilai karakter yang terdapat dalam parno adat pernikahan Siulak adalah antara lain tanggungjawab, disiplin, santun, amanah, Percaya diri, kreatif, peduli, mandiri, berpikir kritis dan suka menolong.
\end{abstract}

Kata Kunci : Parno Adat, Nilai Karakter

\section{PENDAHULUAN}

Pendidikan karakter berarti pendidikan yang bertujuan untuk membantu agar seseorang mengalami, memperoleh dan memeiliki karakter yang kuat yang diinginkan.(Suparno, 2015: 29) Menurut Ki Hajar Dewantara seperti yang dikutip Herdiawanto karakter sama dengan watak. Karakter itu terjadi karena perkembangan dasar yang telah kena pengaruh pengajaran. Jadi, ada unsur bakat yang dipunyai seseorang dan unsur pendidikan selanjutnya. (Herdiawanto, 2010:23)

Selain pada lingkung atau ranah pendidikan formal, proses pendidikan karakter juga ditemukan dalam kehidupan sosial budaya masyarakat. Indonesia yang dikenal sebagai bangsa yang kaya akan nilai-nilai budaya dapat dipastikan memiliki wujud pendidikan karakter yang sangat beragam.(Kusuma, 2007: 16) Demikian juga halnya dengan kabupaten Kerinci. Salah satu hal yang menarik dalam kehidupan sosial masyarakat yang ada di kabupaten Kerinci umumnya dan masyarakat kecamatan Siulak khususnya bahwa dalam acara adat pernikahan terdapat adanya parno adat yang diucapkan secara lisan yang tersirat makna pendidikan karakter bagi kehidupan sosial masyarakat terutama bagi calon penganten.(Efrison, 2009: 45) 
Parno adat termasuk ke dalam salah satu Folklor yang ada diIndonesia. Folklor berasal dari bahasa inggris"Folklore" yang berasal dari kata "Folk" dan "Lore". Folklor berarti sekelompok orang yang memiliki ciri pengenal Fisik, sosial dan budaya. Sehingga dapat dibedaan dari kelompok laiin. Hal terpenting adalah mereka memiliki suatu tradisi, yakni kebiasaan yang mereka warisi turun temurun sedikitnya dua generasi yang mereka pakai secara bersama. (Dundes dalam Rafiek 2010: 50-51).

Parno merupakan kata sambut-menyambut antara pemangku adat atau pelaksana upacara adat tentang kegiatan yang dilakukan, seperti izin pelaksaan, permintaan dimulai upacara, akhir dari upacara, bahkan sebagai salah satu syarat untuk memohon sesuatu kepada pemangku adat. Parno adat memberikan gambaran tentang bagaimana seharusnya kehidupan masyarakat Kerinci telah diajarkan oleh pendahulu dan Ninik Mamak yang tercantum dalam parno adat yang telah diwariskan turun temurun. Kesemuanya ini menunjukkan bahwa parno adat memiliki peranan penting dalam pendidikan karakter masyarakat kabupaten Kerinci khususnya Kecamatan Siulak. Akan tetapi sebagaimana halnya perkembangan tradisi lisan lainnya eksistensi parno adat di Kerinci terancam punah, hanya orang-orang tertentu yang mampu mengungkapkan parno adat ini. Masyarakat khususnya generasi muda kurang meminatinya. Mereka umumnya lebih menyukai hal-hal yang bersifat kekinian. Sehinga setiap ceremonial adat yang berlangsung hanya berlalu begitu saja tanpa adanya pemaknaan yang baik dari acara tersebut. Padahal dalam tiap kata dan bait-bait pantun yang disampaikan pada acara Parno Adat terdapat pesan-pesan yang mengandung pendidikan karakter dan nesehat-nasehat bagi calon penganten. Oleh sebab itu penulis tertarik untuk menganalisis nilai pendidikan karakter dalam parno adat Siulak dalam penelitian yang berjudul ' Nilai Karakter dalam Parno Adat Pernikahan di Kecamatan Siulak Kabupaten Kerinci”".

\section{KERANGKA TEORI}

- Karakter adalah jawaban mutlak untuk menciptakan kehidupan yang lebih baik didalam masyarakat. Karakter merupakan nilai-nilai perilaku manusia yang berhubungan dengan Tuhan Yang Maha Esa, diri sendiri, sesama manusia, lingkungan, dan kebangsaan yang terwujud dalam pikiran, sikap, perasaan, perkataan, dan perbuatan berdasarkan norma-norma agama, hukum, tata krama, budaya, dan adatistiadat (Salahudin, 2013: 287-288)

- Sastra lisan adalah sastra yang disampaikan dari mulut ke mulut dan pengarangnya bersifat anonim. Sastra lisan ini lahir pada umumnya pada zaman sebelum manusia mengenal tulisan atau pada masa tulisan belum dikenal secara luas dalam masyarakat. Pada zaman itu dikenal dengan tradisi lisan yang salah satu genrenya adalah sastra lisan. Teew berpendapat bahwa karya tersebut berkembang dari mulut kemulut yang berarti sastra itu berkembang melalui kemonikasi penduduknya. Oleh sebab itu, untuk memahami sastra lisan harus memahami terlebih dahulu bahasa yang menjadi mediumnya dan budaya masyarakat pendukungnya. Dengan kata lain, untuk memahami Parno sebagai sastra lisan Kerinci 
harus memahami bahasa kerinci sebagai medium Parno dan memahami budaya masyarakat kerinci sebagai pendukungnya. (Teew. 2003, 15).

\section{METODE PENELITIAN}

Rancangan penelitian sastra lisan menggunakan rancangan penelitian kualitatif deskriptif. (Arikunto, 2008: 23) Dimana di dalam penelitian peneliti memahami fenomena yang dialami oleh subjek penelitian dengan terjun langsung ke dalam masyarakat Kecamatan Siulak mengumpulkan data melalui wawancara dan pengumpulan Bait. Bait yang berupa teks Parno pernikahan yang ada di kecamatan Siulak. Teknik pengumpulan Baitnya adalah dengan perekaman, pemotretan, pengamatan, pencatatan, dan wawancara. Dalam analisis Bait, sebelum Bait dianalisis terlebih dahulu diterjemahkan oleh orang adat yang ada di Kecamatan Siulak.

\section{TEMUAN DAN PEMBAHASAN \\ STRUKTUR PARNO ADAT PERNIKAHAN KECAMATAN SIULAK}

Temuan penulis dalam penelitian ini adalah teks Parno Adat Pernikahan yang ada di Kecamatan Siulak, Parno Adat Pernikahan di Kecamatan Siulak terdiri dari 32 bait, yang berisikan nasehat-nasehat bagaimana seharusnya adab seorang isteri kepada suami dan adab suami dalam berumah tangga serta aturanaturan dalam kehidupan bermasyarakat. Parno Adat ini telah diwariskan secara lisan secara turun temurun oleh Ninik Mamak dari dahulu hingga sekarang, dimana Parno Adat ini biasa disampaikan oleh orang adat (Ninik Mamak dan Tengganai) dalam acara kenduri pernikahan. Berikut ini adalah ungkapan nya:

Bait 1: Bismilah mulo munyalo, kirai jalo dilipat tigo

Bismilah mulo bakato, kato adat dengan pusako

Bait 2: $\quad$ Nan tuo segeronyo rapat kak rapat jangan di kirai

Kanti satu uhang mudo kak pendapat kurang pandai

Bait 3 : $\quad$ Batuah di ujung tanjung mumikat ayi milih

Jauh di panggin untung, dekat di panggin sihih pahak pulo di panggin kato

Bait 4 : $\quad$ Sini nampak kito lah duduk sigalo malin, parapat kito umah ini

Kcik idak di panggin namo, gdang idak di panggin gla

Idak di tap idak di bilang, sado di lingkung bendung ngan empat

Di sungkut atap bana sanggit, di tanai lantai silpak

Bait 5: $\quad$ Sini nampaknyo ado pulo dih mulayu ngato

Simurup kotonyo duo

Nyandang nyelewang same bajalan

Kanti disuhuh mancang duo

Samo kito lpeh ajat sepangkalan

Bait 6: Ado pulo ndih mulayu ngato

Gdang ayi di sungai landai

Tempat uhang burulang nyalo

Bukan kanti cdik ngan pandai

Kanti punyambung kato spungko

Teretang jalan kubangko, meniti jambak masumai 
Tegak dilua jadi spungko, duduk di dalam jadi teganai

Bait 7 : $\quad$ Belum pulonyo lentik cinak taji

Belum pulonyo landai cinak dulang

Belum pulonyo cdik cinak kanti

Belum pulonyo cdik cinak kawan

Bait 8: Asuk gdang galga gading, di tindih balako galo

sirpah baku tak kutak, sikutak parapit tudung

sembah ku ini mulai tiletak, sejak pangkah lalu ke ujung

Bait 9: $\quad$ Lalu ke ujung pelinteh pelintang

Panjaro pembelelaian

Bahiris bakirang panjang, panjang ngan tengan tigo puluh

Sederet bendung ditepi, segenggam uang di tengah

Tigo genggam persak kain

Bait 10: Ampunlah saya kepada depati, ninik, mamak

Pegawai dan ulu balang, seisi rumah ini

Kcik idak di sebut namo, gdang idak di sebut gla

Sado di lungkung bendung empat

Atap bajait dengan kato bubung bakupak srak

Balindin, balantak ado butiang batang pasko

Bait 11: Adat umah basendi batu, umah basendi bahaluan umah batiang batiganai

Parit babintang dengan pasko, bapaga dengan lakeng

Jalan panjang bakandang srak, sumo ti genang paga malu

Surau iluk tempat ibadah

Bait 12: Gunung rayo mentuk mudik, gunung merapi mentuk ili

Pengang dapat empat selapah helai kain

Tatunggu tanah rajo tanah juang

Ba iku ba aka pulo, iluk iko pegang pakai mano pegang kito dalam sulak

Bait 13: Batemu pukat dengan lukah baru di sirat dalam jalo

Butemu adat dengan kitabullah baru di bilang ajat sepangkalan

Bait 14 : Idak dibilang usul dengan asal

Jangan samo makan bkeh malin, cinak anyut tengah

Tibun-tibun tigelam idak nyo ujung dengan pangka

Idak pulo wajib pakai kito

Bait 15: Mano dengan wajib pakai di kito tbit ayi dari ulu

Tbit gtah dari batang tbit kato dari mulo

Mano bara mulo kato ado pun yang kumah ini

Ado munahu anak gadih cinak munahu lama sigelembung

Menentukan uhang masuk uhang klua

Kalu dak ntu uhang masuk uhang klua

Same lama disilat api, jangan-jangan samun api makan skam lah bamaro mako tau, Kayo dapat ninik mamak buih malu

Bait 16: Adat munaruh anak bujang, cinak munaruh pipit jantan idak busarang

Kbau gdang idak bukandang, ili lpeh mudik tilampau

Ili lah timaro, mudik lah tiulu, same uhang di lecut tali

Dilentung tambang lpeh

Bait 17 : Mancari lawah bagando rato bakilat ikan di lubuk 
Bamain burung tengah padang, tikejut tigemang raso itu

Bait 18 : Ilang jejak tepat di rumah tanggo ini, di sini langkah dengan bajilo, pajalam dengan bagaji ado papatah alam kerinci

Seiring dengan merbah, balam lalu merbah mandi

Seiring salam dengan sembah sembah nak lalu salam kembali

Bait 19: Muju tak dapat diraih, malang tak dapat di tulak

Muju jugo dingan tijadi, kendak nyo buduo jugo ngan balaku

Bait 20: Adat tuo bakarau mudo baka jiwa, dapat budi katuju baso

Ktek rawan buku lanca,lawan lumah mulailah burisi sirih

Ayi suki di tebing tinggi, ayi anak kancak lah nyusu anak kbau

Lah munyantak kcik lah katuju, gdang pulo lah tiragak

Taro manyuruh galah laku, sirih taulu kato tibo

Idak nyampang gajah di hulu, idak mulai gajah di muaro

Bait 21: Idak rampo pucuk dari enau, idak rampo puting dari ulu

Tgak munurut pancing duduk, munurut garis sipanjang adat

Adat siulak tanah sekudung, di mano bumi dianyah di situ langit di junjung

Bait 22: Dimano adat di situ lumbago dituang

Dimano tembilang dicacak disitu terman tumbuh

Dimana aturan disutu diturutkan

Dimana bertempat tinggal disitulah aturan diturutkan

Bait 23: Tutuk ahi spetang ini, lah jadi unding dingan cinok induk dingan bapak serto anak jantan tiganai umah

Rajo langkat sutan langkat simendo payo kumbuh

Mak ku kato dingan mufakat, bulat ayi kapambuluh

Rajo langkat sutan langkat simendo payo kumbuh

Mak ku kato mufakat, bulat ayi kapambuluh

Bait 24: Tepat petang kamis malam jum 'at

Di tikah anak baduo ini

Dicari siak dingan adil, wali dingan bersih, imam dingan batigo, pegawai dengan barempat serto suluh bindang dalam negri

Tikah makbul ijab dijawab mulailah secara adat

Breh sipinggan ayam siku, siku jantan siku batino

Siku kanadulang laut, disini anak dagang tibuang hino disini pulo badan tipaut

Bait 25: Pasang dap pasang balito, uhang bagudang ditebing tinggi

Tika tikembang lek tibo, bahu senang rasonyo hati

Tentang anak baduo ini mintak mak saiyo sakato saunding

Ili sirentak satang mudik sirengkuh dayung

Mak lantah lukah di bingkai

Buhuk bingkai dipanyalin, lapuk pulo bungo dipangarang

Ini nampak pintak ninik mamak pati

Bait 26: Penghulu mintak mak nyo biak

Kembang sugih kayo nampak imbun

Batukik bubung umah batu pulo bubung balik

Ini nampak sari ado sari banamo

Bagla sari ini batuka, mano sihih ini pulo ajat gla

Gla dingan batino agi gadih minin lh umah tanggo 
Tinggan pulo kelakun agi gadih

Jang pulo samon dingan gadih uhang bahun

Pantang niah ahi petang baletuh nyahap pintu

Balesuh mungenyut lantai same merindu-rindu sayut

Bait 27: Taruh tiru tureh tiladang, ambak anyam timu gantih

Bapiuk gdang batungku jarang

Bakembang lapik bakembang tika

Kawah batungkat bsi, kumah batungkat penyap

Tau basenduk basaji nasi, nempahkah kau anak lakinyo

Malpeh mendah pgi, pgi munantin mendah balik.

Balik petang terhadap lakinyo sedang payah jangan batuik

Sedang bapeluh jangan butanyo

Same tinju gdang lekat dikapalok

Kalu nak batanyo nanti payah menti dan tantik pulo nyo dam

Dikapak jugo paralu kawo

Uang berbunyi terhalang, mengambak, mengayam mengantih

Bait 28: Tentang anak laki-laki sari ado, sari bunamo sari ado sari bagla

Ahi ini batuka namo sahin inilah jugo baanjak gla salamo agi bujang

Mininlah baumah tanggo tinggan pulo kelakun agi bujang

Jangan pulo samon bujang uhang bahun

Pantang nian ahi malam diambik situ dingan seruling

Ditekin tanggu dingan panjang, ili laman mudik laman

Masuk irung kalua irung, sado asuk sado gantung

Sado tkuk sajo jingo, sado puma sado disuhu

Same tisuhu kandang jawi awak pulo dicipak

Dekat pulo pantang anak minin

Kayu aro dilerang bukit taman bungo dikiluk tigo

Idak busuo jadi punyakit namun buso jadi punano

Bait 29: Ini nampak pado ahi ini, lah duduk pulo sko simendo. Enam pulo perkaro

1. Sindo gajang gdang, aso gdang mak nando

Aso tinggi mak ngbah, gpuk mak muang

Cdik mak muang kawan idak pulo wajib pakai kito

2. Sindo ayam jantan, asa kukuk garang piyat anggah

Iku nyimba taji tajam, pantang nyan ngimak kawah

Kito lah ngirai kalepak idak pulo wajib pakai pado kito

3. Sendo kacang miyang tinggi kanti mak di papeh

Pucuk kanti samo gdang dililit batang

Kanti ndah mak kanti ditukuh pulo pucuk kanti idak ugo wajib pakai kito

4. Sendo langau ijau, tau diumah tanggonyo lah

Idak ndak saili samudik idak tau di sanak family idak ugo wajib pakai kito

5. Sindo kucing kuruh ahak cuguk lapu tulah

Ndak saili samudik dingan uhang semakan seminum

Sikumat dingan gawe kito, ahak cuguk kak lapu

Same kito dipti nak api di bayak nak ayi lidih

Lekat pulo pantun anak minin

Burung berak burung kerabo katigo burung ijau 
Batino masak jangan di tunggu masak nasi taulah uhang ngimbau Idak pulo wajib pakai kito

6. Sindo tanggo rapek, tau mapahkah anak buah anak punakan

Tau diireng dingan bayingkato, sampai tau tempat batuik, pandai tempat batanyo, bakumpu iyo nyo limba, bauleh iyo nyo panjang

Gdang tempat busanda imbun tempat buteduh Wajib pakai pado kito

Bait 30: Sini nampak nyo lencang duo, lencang tak duo tak

Kalau di entang mbuhnyo panjang

Baiknyo pulo kito kumpah mak nyo singkek

Bait 31: Durian ditengah padang, akanyo batimbun-timbun

Kainnyo lah dipinggan, palanta lah tiajun

Mintak di bao doa berkat doa silamat

Bait 32 Ntah ado mumikat baru mumikat lamo, mati gdang mati kcik

Mati iluk mati prantau samo dijago

Mati digunung dingan munca, mati dilaut dingan merbo

Samo di dijawat serkah sengguh mano ado, kalu ado pahalo serkah mintak di kadiyah kepado ahli kubur

Hangat mintak di dingin, sempit mintak dilapang mintak dilpeh sikso kubur (Syahyar Adni, Tuo Tengganai, Wawancara)

\section{Nilai Karakter Dalam Parno Adat Pernikahan Kecamatan Siulak}

Parno adat pernikahan di Kecamatan Siulak secara teori merupakan bagian dari Folklor yang ada di Nusantara dimana parno adat ini pewarisannya dilakukan secara lisan. (Sulistyorini, 2017:3). Folklor yang diwariskan oleh nenek moyang tentunya mempunyai fungsi tertentu. Apabila dikaji dapat dilihat adanya muatan nilai-nilai luhur, nilai-nilai moral dan dedaktik. Hal ini juga dapat dijadikan sebagai kontrol sosial dalam bertingkah laku maupun bertindak. (Sulistyorini, 2017: 3)

Parno-parno yang penulis tulis dalam penelitian ini memperlihatkan bahwa antara adat Kerinci, pendidkan karakter dan agama Islam memiliki hubungan yang erat. Dimana terdapat sumbangan berharga dari ajaran Islam dalam melengkapi berbagai aktifitas adat di Kerinci. Dalam parno adat terdapat makna-makna yang mengandung ungkapan nasehat bagi calon penganten, baik bagi wanita maupun mempelai pria sebagaimana yang dijelaskan berikut ini:

Bait 1. Dalam setiap mengawali pekerjaan hendaklah memulai dengan membaca bismillah dengan tujuan meminta kepada Allah untuk keberkahan setiap pekerjaan yang kita lakukan. Bait 2. segala sesuatu atau urusan sebaiknya diselesaikan dengan orang yang lebih tua, karena lebih berpengalaman dari yang muda. Dalam menyelesaikan suatu pekerjaan atau urusan hendaklah bertanya kepada orang yang telah berpengalaman agar apa yang kita kerjakan bisa lebih efektif dan efisien dan dapat mencapai tujuannya dengan tepat, begitu juga bagi orang tua yang telah berpengalaman agar dapat memberi petunjuk dan bertanggungjawab dalam membimbing anak muda. Pada bait Bait 1 dan 2 terdapat karakter kesantunan. Hal ini sama dengan teori yang diungkapkan oleh Markhamah dan Atiqa Sabardila (2013:153) bahwa kesantunan merupakan suatu 
cara yang dilakukan seorang penutur saat berkomunikasi supaya lawan bicara penutur atau pendengar merasa dihormati, nyaman dan tidak menimbulkan kesalahpahaman. Makna pada bait ke 2 sejalan dengan apa yang diajarkan di dalam Islam sebagaimana hadist Nabi yang artinya :

Rasulullah shallallahu 'alaihi wasallam bersabda: "Jika amanat telah disia-siakan, tunggu saja kehancuran terjadi." Ada seorang sahabat bertanya; 'bagaimana maksud amanat disia-siakan?' Nabi menjawab; "Jika urusan diserahkan bukan kepada ahlinya, maka tunggulah kehancuran itu." (BUKHARI-6015)

Pada bait ini juga terdapat nilai karakter amanah, sebagaimana yang diungkapkan oleh Mustafa Al-Maraghi bahwa amanah itu ada tiga macam, amanah kapada Allah, amanah kepada manusia lainnya dan amanah kepada diri sendiri. Salah satu bentuk amanah kepada orang lain adalah pemimpin berlaku adil terhadap masyarakatnya, ulama berlaku adil terhadap orang-orang awam dengan memberi petunjuk kepada mereka untuk memiliki i'tikad yang benar, memberi motivasi untuk beramal yang memberi manfaat kepada mereka di dunia dan akhirat, memberikan pendidikan yang baik, menyuruh berusaha yang halal serta memberikan nasihat-nasihat yang dapat memperkokoh keimanan agar terhindar dari segala kejelekan dan dosa serta mencintai kebenaran dan kebaikan.

Bait 3 yang jauh dipanggil mendapatkan keberuntungan, yang dekat diberi tahu bahwa acara pernikahan akan dilaksanakan. Dalam bait ke 3 ini memberitahukan agar dalam melakukan suatu perhelatan atau acara baik seperti pernikahan hendaklah memberi tahu masyarakat banyak agar bisa bersama-sama mensukseskan acara tersebut. Bait 4. Di dalam suatu rapat tidak diperpanjang mukadimahnya segera selesaikan permasalahan yang mau di bahas. Dalam menyampaikan suatu maksud mengapa acara itu dilaksanakan hendakalah menjelaskannya secara singkat, padat dan tepat jangan berbelit-belit sehingga orang sulit untuk mengerti.

Bait 5. Hasil keputusan yang telah disepakati oleh orang banyak dari satu orang yang memberi pendapat (orang yang lebih tua). Dalam bermusyawarah hendaklah mencari kesepakatan bersama dengan petunjuk orang yang lebih tua dan berpengalaman dalam menjalanakan acara yang pernah sebelumnya. Bait 6 . Orang yang melaksanakan perhelatan atau acara memanggil atau mengundang keluarga dekat dan jauh serta masyarakat sekitar untuk makan bersama sebagai wujud rasa syukur atas segala niat baik yang tersampaikan hajatnya.

Pada bait 3-6 menjelaskan bahwa dalam adat Kerinci Khusunya Kecamatan Siulak telah diwariskan kehidupan sosial yang mengajarkan kebersamaan, dalam hukum adat dalam melaksanakan suatu perhelatan harus memberitahukan orang banyak artinya orang-orang sekitar tempat tinggal, keluarga dekat dan jauh. Pada bait ke 3 sampai 6 ini mengajarakan karakter peduli. Peduli adalah sebuah nilai dasar dan sikap memperhatikan dan bertindak proaktif terhadap kondisi atau keadaan di sekitar kita. Peduli adalah sebuah sikap keberpihakan kita untuk melibatkan diri dalam persoalan, keadaan atau kondisi yang terjadi di sekitar kita (Mustari: 2014, 129). 
Orang-orang peduli adalah mereka yang terpanggil melakukan sesuatu dalam rangka memberi inspirasi, perubahan, kebaikan kepada lingkungan di sekitarnya. Ketika ia melihat suatu keadaan tertentu, ketika ia menyaksikan kondisi masyarakat maka dirinya akan tergerak melakukan sesuatu. Apa yang dilakukan ini diharapkan dapat memperbaiki atau membantu kondisi di sekitarnya. Ketika diundang untuk hadir diacara perhelatan maka seseorang akan datang untuk ikut membantu mensukseskan acara tersebut.

Bait 7. Bukannya orang cerdik dan pandai untuk penyambung lidah tuan rumah Kalau di luar jadi orang biasa di dalam rumah jadi teganai. Untuk menyampaikan hajat sepangkalan dalam suatu acara bukanlah orang pemilik acara tersebut yang langsung menyampaikannya tapi mewakilkan kepada orang cerdik pandai atau tengganai rumah yang didahulukan selangkahdan maksud acara tersebut dilaksakan. Bait 8. Bukannya orang cerdik pandai, karna tuan rumah menyuruh mengutarakan hajatnya. Sepangkalan mewakilakan penyampaian hajatnya kepada tengganai rumah karena begitulah adat yang berlaku disana, bukan berarti sepangkalan tidak bisa menyampaikan sendiri tetapi untuk menghargai tengganai rumah.

Bait 9. apa yang dibahas dalam mengutarakan hajat harus sampai ke ujung pangkal permasalahannya. Dalam menyampaikan hajat yang hendak dilaksanakan maka harus jelas dari awal hingga akhir sehingga tidak terjadi salah paham. Bait 10. Kalau tidak menerapkan yang sebenarnya dalam adat maka kita akan membayar hutang, maka untuk itu berhati-hati menyampaikan kata sebelum terjadi supaya apa yang kita lakukan akan lurus di jalan yang benar. Dalam menyampaikan dan dalam melaksanakan suatu prosesi acara maka hendaklah sesuai dengan adat setempat, jika menyalahi aturan yang berlaku dalam adat setempat maka sepangkalan akan di denda oleh masyarakat.

Bait 11. Penutupan dalam sebuah musyawarah atau rapat dan memohon maaf bila ada kesalahan dalam perkataan parno adat. Setelah menyampaikan hajat dan setelah malaksakan acara maka sepangkalan meminta maaf jika dalam menyampaikan atau selama acara berlangsung terdapat salah dan khilaf. Bait 12 . Adat orang berteganai rumah, rumah yang ditinggal oleh ibu/ bapak di waktu masih hidup harus di beri tahu teganai rumah, tidak boleh semaunya sendiri. Dalam melakukan sesuatui hal maka harus memberi tahu tengganai rumah sebagai penghormatan kepada orang yang didahulukan selangkah.

Bait 13. Pedoman pemerintah pegangan teganai rumah. Dalam melaksanakan suatu acara atau memutuskan suatau perkara maka adat yang berlaku di Kecamatan Siulak itulah adat yang dipegang sebagai pedoman oleh tengganai rumah untuk mengarahkan anak kemenakan. Bait 14. Apa bila sudah berkumpul di dalam panggilan taganai ke rumah setelah itu baru hajat tuan rumah di sampaikan. Dalam menyampaikan hajat memang haruslah tengganai rumah yang menyampaikan jika bukan tengganai rumah yang menyampaikan maka hajat tersebut tidaklah sah dan dianggap menyalahi aturan adat yang berlaku.

Pada bait 7 sampai 14 menjelasakan posisi dan kedudukan tengganai dalam suatu keluarga. Tengganai adalah saudara perempuan dari isteri, sedangkan Tuo Tengganai adalah para orang tua dari sekum,pulan tengganai-tengganai dari keluarga-keluarga disebuah dusun, kampung, Desa atau Kelurahan. Pada bait 7 
sampai 14 mengajarkan karakter Tanggungjawab, tanggungjawab seorang tengganai terhadap saudara perempuannya, mengarahkan, mengajun arah dan langkah. Tanggungjawab bisa diartikan sebagai konsekuensi yang harus diterima atau dijalankan terhadap apa yang sudah dilakukan atau dijalani. Kita sering mendengar kata "lepas tanggungjawab" artinya tidak mau mempertanggung jawabkan apa yang sudah dilakukan (lempar batu sembunyi tangan). Pembentukan nilai tanggung jawab tidak dapat dilepaskan dari proses pembelajaran baik di rumah maupun di sekolah (Lockona, 2013: 95).

Bait 15. Apa bila hajat sudah disampaikan tidak jelas ujung dan akhirnya didalam adat itu tidak di sahkan bisa mengacaukan. Jika dalam penyampaian hajat yang hendak dilaksanakan tidak jelas maksud dan tujuannya maka hajat tersebut dianggap tidak sah.Bait 16. Apabila sudah tahu adat di desa apa pun masalah harus di beri tahu baik atau buruk nya kepada teganai rumah supaya orang yang masuk itu agar tidak melimpahkan malu dalam desa. Ketika menerima orang baru atau berminantu maka tengganai rumah hendaklah menyampaikan adat setempat yang berlaku kepada orang semenda agar orang tersebut tidak menyalahi atauruan yang berlaku ketika bersikap dan bertindak karena bisa membuat malu.

Bait 17. berkeluarga di langsungkan secara adat jangan orang desa itu memfitnahkan di dalam desa. Jika suatu keluarga memiliki anak laki-laki yang pantas untuk dinikahkan maka hendaklah orang tua mencarikan jodohnya dan menikahkan anak mereka tersebut agat tidak menimbulkan fitnah.Bait 18. Siapa yang tidak kenal harus masuk desa dengan aturan supaya jangan orang desa tersebut terkejut melihat orang baru yang tidak tahu dari mana asalnya. Orang yang baru memasuki suatu daerah atau desa maka hendaklah orang tersebut memperkenalkan diri agar masyarakat setempat tidak terkejut dan bisa tau asal usulnya.

Bait 19 Apa pun yang terjadi harus memberi tahu orang desa setempat. Bagi orang yang baru memasuki suatu desa maka apapun yang terjadi harus member tahu masyarakat setempat baik hal baik maupun hal buruk agar tidak menimbulkan sahwa sangka. Bait 20. Kata adat di desa harus di dengar dan dijalankan agar kita di desa di perhatikan oleh orang desa, jangan kehendak kita sendiri yang melaju tak tentu arah. Dalam bersikap dan bertindak maka harus sesuai dengan adat yang yang berlaku ditempat tinggal kita, tidak boleh berbuat sekehendak hati walaupun hal itu benar menurut kita, agar setiap perbuatan kita teraarah dan tertuju dengan baik.

Pada bait 15 dan 20 mengajarkan karakter disiplin, disiplin adalah kepatuhan mentaati peraturan dan ketentuan yang telah ditetapkan. Arti disiplin adalah tingkat konsistensi dan konsekuensi seseorang terhadap suatu komitmen atau kesepakatan bersama yang berhubungan dengan tujuan yang akan dicapai. Disiplin penting bagi perkembangan seseorang karena memenuhi beberapa kebutuhan-kebutuhan tertentu.

Bait 21 Pernikahan rasa perasaan bukan di jodohkan orang tua. Dalam melakukan suatu pernikahan maka pernikahan tersebut harus berdasarkan kehendak kedua mempelai bukan karena dipaksa oleh orang tua atau orang lain. Pada bait 21 ini mengungkapkan bahwa dalam suatu pernikahan tidak boleh ada keterpaksaan, dalam artian kedua mempelai yang menikah memang atas dasar 
keinginan sendiri. Hal ini juga sejalan dengan ajaran Islam yang tertuang dalam hadits Nabi saw.

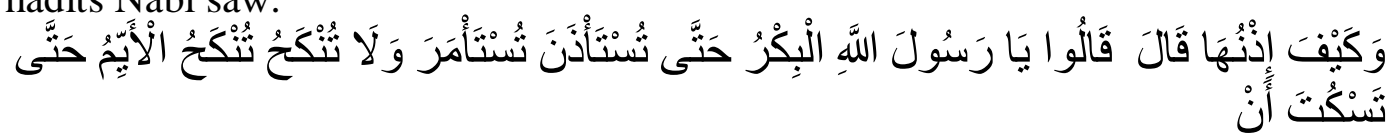

Artinya: "Tidak boleh menikahkan seorang janda sebelum dimusyawarahkan dengannya dan tidak boleh menikahkan anak gadis (perawan) sebelum meminta izin darinya." Mereka bertanya, "Wahai Rasulullah, bagaimana mengetahui izinnya?" Beliau menjawab, "Dengan ia diam." (HR. Al-Bukhari no. 5136 dan Muslim no. 1419)

Bait 22. Dimanapun kita berada aturan disitulah yang harus dipatuhi. Dimanapun berada harus mergaul dengan orang disekitarnya jangan hanya berada di dalam rumah saja dan tidak mengenal keluarga besar. Dimana bumi dipijak maka disitulah langit dijunjung, kita harus berbuat sesuai dengan adat yang berlaku dimana kita tinggal, dan harus bergaul dengan orang sekitar bukan hanya mengenal anggota keluarga saja tetapi harus mengenal tetangga dan warga masyarakat lainnya. Bait 23 Dimana pun berada harus diturut, jangan berpisah sesuka hati tanpa tahu adat setempat. Dalam pergaulan bermasyarakat tidak boleh seseorang menyendiri dan berbuat sesuka hati tanpa peduli dengan orang sekitar, karena hak kita akan dibatasi oleh hak orang lain.

Bait 22 dan 23 mengajarakan karakter peduli dan suka menolong, bahwa dimanapun kita berada maka harus bisa menyesuaikan diri dengan lingkungan sekitar dan mengikuti aturan adat yang berlaku, kita harus bergaul dengan siapa saja dalam masyarakat tersebut bukan hanya keluarga saja.

Bait 24. Telah duduk teganai kedua belah pihak dan sudah bulat kata mufakat dan sudah bisa kita lanjutkan kenduri pernikahan. Untuk melangsungkan suatu pernikahan maka terlebih dahulu bermusyawarahlah kedua belah pihak mempelai, berkumpul dua keluarga untuk memutuskan perundingan sehingga pernikahan bisa dilanjutkan.

Bait 25. Pernikahan sudah di sahkan penghulu. Setelah disepakati hari dan tanggal pernikahan maka pada hari tersebaut akan dilaksanakan pernilakan dan prosesi ijab qabul kedua mempelai yang di sahkan secara agama di depan penghulu dan saksi-saksi. Bait 26. Cukup sekali menikah agar selalu seiya-sekata dan tidak menikah berulang kali. Dalam menjalani bahtera rumah tangga hendaklah kedua mempelai saling melengkapi dan saling mengingatkan agar terus bisa berjalan beriringan sehingga pernikahan tersebut langgeng tanpa harus ada perceraian.

Bait 24 dan 25 menjelaskan adanya fungsi tengganai dalam kehidupan keluarga dan bermasyarakat, untuk menentukan suatu pernikahan bukan hanya kesepakatan dua mempelai dan orang tua mempelai saja tetapi harus ada kesepakatan tengganai dan ninik mamak kedua belah pihak karena tanpa adanya kesepakatan tengganai dan ninik mamak kedua belah pihak maka pernikahan tersebut dianggap cacat secara adat dan bisa didenda secara adat.

Bait 27. Kalau sudah berumah tangga, jangan berkelakukan sepertin masih gadis dan laki-laki juga harus meninggalkan kebiasaan seperti bujangan. Harapan 
dari kedua belah pihak keluarga hendaklah mempelai yang sedang melangsungkan pernikahan dikarunia anak yang shaleh dan shalehah dan hendaklah kedua mempelai bisa saling manjaga, tidak berkelakuan seperti gadis dan bujang lagi. Bait 28. Kalau suami baru pulang kerumah jangan bicara keras-keras dan tunggu lelahnya hilang dan tunggu suami dengan tenang serta jangan marah-marah kepada suami. Adat dalam berumah tangga seorang isteri harus berlakulemah lembut kepada suaminya, ketika suami pulang tidak boleh langsung menanyakan berapa penghasilan hari ini tapi terlebih dahulu layani suami seperti dengan membuatkan minum dan biarkan lelahnya hilang terlebih dahulu.

Bait 29. Kalau laki-laki telah berumah tangga jangan berkelakuan seperti masih bujang, kelakuan masih bujang ditinggalkan dan contoh kelakuan yang baik di desa setempat. Seorang laki-laki jika sudah beruamah tangga maka harus meninggalkan perangai ketika masih bujang, jangan suka keluar malam dan bergaul dengan yang tak pantas tapi bergaullah sesuai adat setempat.

Bait 30. Bagian 1 Seperti gajah besar, mentang besar ingin menyenggol, Merasa tinggi ingin merebahkan, gemuk ingin membuang, Cerdik membuang kawan, tidak pula wajib untuk kita pakai. Maksudnya adalah Seorang semenda tidak boleh berlagak sombong terhadap keluarga pasangannya walaupun dia mempunyai kelebihan. Bagian 2. Seperti ayam jantan, kukuk keras jambul tegak. Ekor kembang,tajinya tajam, pantang melihat ke bawah. Kita sudah mengerai kelepak, tidak pula wajib untuk kita pakai. Maksudnya Seorang menantu janganlah berlagak bagak (sombong) terhadap keluarga Isterinya. Bagian 3. Seperti kacang miyang, tinggi teman mau dipangkas, Pucuk teman sama besar dililit batang, Teman rendah supaya teman tak bisa naik ke puncak, tidak juga wajib untuk kita pakai. Maksudnya adalah Seorang menantu tidak boleh memilihmilih pkerjaan dalam menjalankan tanggungjawabnya sebagai pemberi nafkah. Bagian 4. Seperti nyamuk hijau, tahu hanya dengan rumah tangganya saja, Tak mau seilir semudik, tidak tahu sanak famili, tidak juga wajib untuk kita pakai, Tidak boleh hanya tahu istrinya saja tetapi tidak tahu keluarga dan juga orangorang desa setempat.Seorang suami atau isteri tidak boleh hanya tahu dengan pasangannya saja akan tetapi harus mengenal semua keluarga dan warga setempat agar terjalin silaturrahmi yang baik anata kedua belah pihak. Bagian 5. Kalau istri masih ada pekerjaan didapur tidak boleh diperhatikan, kalau sudah masak kita pasti dipanggil untuk makan.

Pada bait 27 sampai 30 inilah terdapat nasehat-nasehat bagaimana adab seorang isteri dan suami ketika telah berumah tangga, mengajarkan karakter disiplin, peduli, amanah, berpikir kritis dan kreatif, tanggungjawab, kesantunan, suka menolong dan mandiri sebagaimana yang telah dijelaskan di atas.

Pada Bait 31- 33 adalah kata penutup dimana dianjurkan agar tidak memperpanjang kata-kata, dan minta kepada tamu yang hadir agar didoakan keselamatan bagi keluarga yang memiliki hajat. Tuan rumah meminta doa untuk keluarga yang telah meninggal. Dalam menbacakan doa maka sepangkalan meminta kepada yang membacakan doa juga berdoa bukan hanya untuk kelancaran acara tetapi juga untuk arwah keluarga yang telah meninggal agar diberi ketenangan. 


\section{PARNO ADAT SEBAGAI SASTRA LISAN KECAMATAN SIULAK}

Parno adat Kerinci adalah ungkapan yang mengandung pesan, atau nasihat yang bernilai etik dan moral, serta sebagai alat pemaksa dan pengawas normanorma masyarakat agar selalu dipatuhi. Isi ungkapan Parno adat Kerinci meliputi peraturan bertingkah laku dalam kehidupan sehari-hari masyarakatnya dan kaidah-kaidah hukum atau norma-norma, senantiasa ditaati dan dihormati oleh masyarakatnya karena mempunyai sanksi. Ungkapan-ungkapan Parno adat Kerinci dapat berupa peribahasa, pantun atau pepatah petitih.

Parno adat Kerinci juga merupakan pandangan hidup atau pandangan dunia yang mendasari seluruh kebudayaan Kerinci. Parno adat Kerinci juga merupakan sarana masyarakatnya dalam merefleksikan diri akan hakikat kebudayaan, pemahaman mendasar dari pesan dan tujuan dari sebuah kebudayaan (Amali Muadz).

Selain Parno Adat Pernikahan bentuk lain Parno adat Kerinci adalah mengenai pengambilan keputusan dalam pemerintahan, Parno adat Kerinci menyebutkan bahwasanya: "Berjenjang naik betanggo turun, turun dari takak nan di atas, naik dari takak nan di bawah", Parno adat tersebut mempunyai pengertian bahwasanya dalam mengambil keputusan terdapat tingkatan-tingkatan pengambilan keputusan. Tingkatan pengambilan keputusan ini misalnya tingkat pengambilan keputusan yang tertinggi, yaitu Alam nan Barajo, sampai dengan sebuah pengambilan keputusan pada tingkatan yang paling bawah Anak nan Berbapak, Kemenakan nan Bermamak.

Parno adat lainnya yang sangat banyak jumlahnya, misalnya Parno adat yang mengatur dalam kehidupan berkelompok (masyarakat), dalam hal pergaulan sehari-hari, dan sebagai bentuk nasihat dalam menjalani kehidupan di dunia. Parno adat merupakan salah satu bentuk warisan leluhur yang tidak boleh dibuang begitu saja. Harus dilestarikan dan diturunkan kepada anak cucu, agar mereka mengetahui betapa generasi tua mereka adalah generasi yang menjunjung tinggi adat dan budaya ketimuran.

Parno adat pernikahan Kecamatan Siulak merupakan bahasa petatahpetitih yang telah disusun oleh ninik mamak dan orang-orang terdahulu dalam bentuk pola pantun menggunakan bahasa yang indah dalam menyampaikan pesan kepada calon pengantin dan bernilai bagi masyarakat, khususnya masyarakat Kerinci. Parno sangat dikenal dan frekuensi pemakaiannya cukup tinggi dalam kehidupan sosial bermasyarakat di Kerinci, terutama bagi masyarakat Kecamatan Siulak.

Parno dalam masyarakat Kerinci diungkapkan melalui bahasa lisan yang berupa bahasa kiasan dan perumpamaan di dalamnya. Jadi, Parno Kerinci diwariskan dari generasi ke generasi berikutnya dari mulut ke mulut dalam budaya Kerinci. Berarti, Parno merupakan tradisi lisan Kerinci yang menjadi bagian dari budaya Kerinci. Di dalam Parno berisi ungkapan adat untuk menyampaikan hajat tetapi isi di dalam nya merupakan kata-kata yang bukan menandai seseorang untuk menyampaikan hajat. Saat berParno tidak semua masyarakat mengetahui apa maksud dari kata-kata Parno tersebut. Hal ini sangat disayangkan bagi 
masyarakat Kecamatan Siulak sebagai pewaris sastra lisan berParno yang hanya sekedar mengetahui tanpa tahu bagaimana bentuk dan maknanya.

Parno merupakan ungkapan adat yang berisi hajat seseorang. Ungkapanungkapan di dalam Parno berupa pribahasa, bahasa kiasan dan pepatah petitih. Sama halnya dengan seloka, masyarakat Jambi mengenalnya dengan seloko. Seloko adat Jambi berupa ungkapan yang mengandung pesan, atau nasihat yang bernilai etik dan moral, serta sebagai alat pemaksa dan pengawas norma-norma masyarakat agar selalu dipatuhi.

Selain itu, terlihat bahwa kedudukan dan fungsi Parno pada masyarakat Kerinci sangatlah penting dalam pewarisan nilai-nilai adat dan budaya Kerinci kepada generasi selanjutnya. Masyarakat Kerinci sebagai pewaris sastra lisan berParno sebagiannya juga telah mengabaikan sastra lisan ini. Ini terlihat jarangnya dan hampir tidak ditemukan lagi tradisi berParno dalam masyarakat Kerinci. Padahal berParno banyak mengandung nasihat yang bernilai etik dan moral yang masih dibutuhkan pada masa sekarang dan yang akan Baitng, terutama norma-norma adat pada prilaku yang positif yang mengandung nilai-nilai moral dalam kehidupan sosial bermasyarakat.

Bentuk pada parno dilihat menggunakan kajian tipografi berdasarkan ciriciri seloko dan ungkapan Melayu atau peribahasa yang meliputi pepatahpetitih,perumpamaan, petuah dan kias yang mengkaji baris, diksi, jumlah kata, jumlah suku kata, irama dan persajakannya. Sedangkan dari segi maknanya peneliti menggunakan makna kontekstual yang bersifat gramatikal dalam menganilisis makna. Dalam menganilisis bentuk berdasarkan tipografinya ditemukan kesamaan dengan ciri-ciri seloko dan ungkapan Melayu yang mengandung kata-kata adat, ketentuan-ketentuan adat, nasihat, pedoaman, petunjuk maupun bercerita tentang kehidupan sosial.

\section{KESIMPULAN}

Struktur parno adat pernikahaan di Kecamatan Siulak berbentuk diksi dimana kata-kata yang dirangkai dipilih sehingga bisa menjadi seindah bait-bait kata berbentuk pantun dan juga prosa yang mengkiaskan bahagaimana seharusnya hak dan kewajiban antara suami isteri, bagaimana tanggungjawab keduanya dalam menjalani kehidupan beruimah tangga. Nilai-nilai karakter yang terdapat dalam parno adat perniakahan Siulak adalah antara lain tanggungjawab, disiplin, santun, amanah, Percaya diri, kreatif, peduli, mandiri, berpikir kritis dan suka menolong. Nilai-nilai karakter tersebut tidaklah nampak secara nyata namun dikiaskan dalam bentuk kata-kata peribahasa dan pantun yang mana tujuannya adalah mengajarkan pasangan yang akan menikah bagaimana nantinya membina karakter yang baik agar terjalin hubungan yang baik antara dua keluarga.Parno adat Kerinci juga merupakan pandangan hidup atau pandangan dunia yang mendasari seluruh kebudayaan Kerinci. Parno adat Kerinci juga merupakan sarana masyarakatnya dalam merefleksikan diri akan hakikat kebudayaan, pemahaman mendasar dari pesan dan tujuan dari sebuah kebudayaan. 
Mina Zahara, Nilai Karakter Dalam Parno Adat Pernikahan Di Kecamatan Siulak Kabupaten Kerinci

\section{DAFTAR PUSTAKA}

Arikunto, Suharsimi. 2008. Prosedur Penelitian Suatu Pendekatan Praktek Jakarta: Rineka Cipta.

Aunillah, Nurla Isna. 2011. Panduan Menerapkan Pendidikan Karakter di Sekolah. Jogjakarta: Laksana

Elda Nurfalara, Bentuk dan Makna Parno Adat dalam Masyarakat Pulau Tengah, Fakultas Ilmu Budaya Universitas Jambi,

Efrison, Jati Diri Masyarakat Kerinci Dalam Tradisi Lisan, Pascasarjana Universitas Sumatera Utara, Medan, 2009.

Herdiawanto, Heru. dkk. 2010. Cerdas. Kritis. Aktif Berwarganegara. Jakarta : Erlangga.

Kesuma, Dharma. 2011. Pendidikan karakter Kajian Teori dan Praktek di Sekolah. Bandung:Remaja Rosda Karya.

Kusuma, Doni. 2007. Pendidikan Karakter: Strategi Mendidik Anak di Zaman Globa. Jakarta: Grasindo.

Koentjaraningrat, 2000, Pengantar Ilmu Antropologi, Jakarta : Rineka Cipta

Lickona, Thomas, 2013, Pendidikan Karakter Panduan Lengkap Mendidik Siswa Menjadi Pintar dan Baik, Bandung: Nusa Media,

Mu`in, Fatchul. 2011. Pendidikan Karakter Konstruksi Teoritik \& Praktik. Jogjakarta: Ar-Ruzz Media

Mustari, Mohammad. 2014. Nilai Karakter Refleksi Untuk Pendidikan. Jakarta: Rajawali

Nasution, 2010. Berbagai Pendekatan Dalam Proses Belajar Mengajar. Jakarta: Bumi Aksara.

Nogroho, Garin dan Elfiandri. 2012. Pendidikan karakter:Kerangka. Metode dan Aplikasi Untuk Pendidikan profesional. Jakarta: Badouse Media.

Ramli, Mansur. 2010. Pengembangan Pendidikan Budaya dan Karakter Bangsa. Jakarta: Kementerian Pendidikan Nasional Badan Penelitian dan Pengembangan Pusat Kurikulum.

Soekmono, 2003, Pengantar Sejarah Kebudayaan Indonesia, Yogyakarta: Kanisius

Sugiyono. 2018. Metode Penelitian Pendidikan Pendekatan Kuantitatif. Kualitatif dan $R \& D$. Bandung:Alfabeta.

Suparno, Paul, 2015. Pendidikan Karakter di Sekolah, Yogyakarta: Kanisius.

Teew, 2003, Sastra dan Ilmu sastra, Jakarta: Pustaka Jaya

Wahyudi (2019). Naskah Muqaddimah Al-Mubtadin, (Jakarta: Perpustakaan Nasional Republik Indonesia. 